\title{
Local Reaction
}

National Cancer Institute

\section{Source}

National Cancer Institute. Local Reaction. NCI Thesaurus. Code C50419.

A regionally-limited response to an antigen, which may include inflammation, induration,

erythema, pruritus or pain. 